\title{
Serum low-density lipoprotein levels, statin use, and cognition in patients with coronary artery disease
}

\author{
Soham Rej' \\ Mahwesh Saleem ${ }^{2,3}$ \\ Nathan Herrmann ${ }^{1,3}$ \\ Anthi Stefatos ${ }^{4}$ \\ Allison $\mathrm{Rau}^{3}$ \\ Krista L Lanctôt ${ }^{1-3}$ \\ 'Department of Psychiatry, \\ ${ }^{2}$ Department of Pharmacology and \\ Toxicology, University of Toronto, \\ ${ }^{3}$ Neuropsychopharmacology Research \\ Group, Sunnybrook Health Sciences \\ Centre, Toronto, ON, ${ }^{4}$ Faculty of \\ Medicine, Université de Montréal, \\ Montréal, QC, Canada
}

This article was published in the following Dove Press journal:

Neuropsychiatric Disease and Treatment

10 November 2016

Number of times this article has been viewed
Aim: Statins have been associated with decreased cognition due to the effects of low concentrations of low-density lipoprotein (LDL) on brain function. This has remained controversial and is particularly relevant to patients with coronary artery disease (CAD), who have an increased risk of cognitive decline and are frequently prescribed statins. This study hypothesized that low concentration of LDL is associated with poor cognition in CAD patients using statins. It also explored the association between high-dose versus low-dose statins on cognition in this population.

Patients and methods: Baseline cross-sectional data from a longitudinal study of 120 statinusing CAD patients were examined (mean statin duration $25 \pm 43$ months). The main outcomes were measures of global cognition and cognitive domains, with poor cognition defined as cognitive performance $\leq 1$ standard deviation below the population age and education adjusted means. A battery of cognitive tests was used to assess verbal memory, executive function, speed of processing, visuospatial memory, and global cognition. Adjusting for age, sex, education, and other covariates, multivariable logistic regression analyses assessed associations between low LDL levels $(<1.5 \mathrm{mmol} / \mathrm{L})$, statin use, and poor cognition.

Results: LDL levels were not associated with global cognition or individual cognitive domains. High-dose statin use was associated with higher visuospatial memory (odds ratio, OR [95\% confidence interval, $\mathrm{CI}]=0.12[0.02-0.66], P=0.01)$ and executive functioning $(\mathrm{OR}=0.25$ [0.06-0.99], $P=0.05)$. This effect was independent of covariates such as LDL levels.

Conclusion: Low LDL levels do not appear to be associated with poor cognition in CAD patients using statins. Whether high-dose statin use may have positive effects on cognition in CAD patients could be investigated in future studies.

Keywords: cholesterol, visuospatial cognition, heart disease, psychopharmacology, adverse drug events

\section{Introduction}

HMG-CoA reductase inhibitors (statins) are believed to have positive cognitive effects. Meta-analyses have found associations between statins and decreased risk of cognitive decline and cognitive disorders, ${ }^{1}$ especially with long-term use. ${ }^{2-4}$ These potential protective effects of statins may be related to cerebrovascular health; statin use has been linked with better white matter integrity in community dwelling elders. ${ }^{5}$ Although controversial, ${ }^{6}$ some early evidence has suggested that statins may be useful in the prevention of dementia in high-risk populations, ${ }^{7}$ particularly in patients with poorly controlled hypercholesterolemia. ${ }^{8}$ This may be explained in part by the pleiotropic effects of statins, such as improved endothelial functioning, atherosclerotic plaque
Correspondence: Krista L Lanctôt Department of Psychiatry, University of Toronto, 2075 Bayview Ave, FG-08, Toronto, ON M4N 3M5, Canada $\mathrm{Fax}+$ I 4164806022

Email krista.lanctot@sunnybrook.ca 
stability, decreased oxidative stress, inflammation, and inhibition of vascular thrombogenic response, in addition to their cholesterol-lowering effects. ${ }^{9}$

On the contrary, statins have been recently associated with worse cognition due to their low-density lipoprotein (LDL) cholesterol-lowering effects. It is thought that low LDL levels (eg, $<1.5 \mathrm{mmol} / \mathrm{L}$ ) interfere with cholesterol and phospholipid concentrations in neuronal membranes, thereby affecting cell signaling and neuronal functioning. ${ }^{10}$ Novel animal data have demonstrated that gene knockout of the LDL receptor may be associated with hippocampal apoptosis. ${ }^{11}$ Recent human studies suggest that statin users are more likely to suffer from cognitive impairment than non-statin users, ${ }^{12}$ with impairments in executive functioning, episodic memory, and other cognitive domains associated with low LDL levels. ${ }^{13,14}$ This remains controversial, as welldesigned prospective longitudinal studies and randomized controlled trials have not necessarily found an association between LDL and cognition. ${ }^{15-17}$

These issues are particularly relevant in those with coronary artery disease (CAD). CAD and cognitive disorders such as Alzheimer's, vascular, and mixed dementias have a shared biological etiology, with both being associated with oxidative stress, inflammation, lipid/glucose dysregulation, endothelial dysfunction, ${ }^{18,19}$ and common genetic risk factors. ${ }^{20}$ As such, CAD patients have a substantially increased risk of Alzheimer's disease and other dementias. ${ }^{21-24}$ CAD patients often have poor white matter microstructural integrity, which in turn has been associated with executive function, processing speed, and other cognitive deficits..$^{25,26}$ Statins are very frequently prescribed in CAD patients. Statin pharmacotherapy in CAD is recommended irrespective of a patient's lipid profile, even in normocholesterolemic patients, as they have been shown to reduce premature death, myocardial infarction, and other cardiovascular events. ${ }^{27}$ Therefore, the risk/benefit of statins vis-à-vis cognitive dysfunction is important in this population.

A small number of studies have examined statins and cognitive dysfunction, ${ }^{3,13}$ with few specifically examining this association in CAD patients as a primary outcome. ${ }^{28}$ Because high-dose statins are often prescribed in $\mathrm{CAD},{ }^{29}$ the potential risk of low LDL levels on cognition are of particular concern. This study hypothesized that low LDL levels will be associated with poor cognition in CAD patients using statins and then examined the association between high-dose versus low-dose statins on cognition in this population. It also explored associations between cognition and other lipid parameters (high-density lipoprotein [HDL], total cholesterol [TC], TC/HDL ratio, and triglyceride levels). ${ }^{13,30}$

\section{Methods}

\section{Study design and study population}

This was a cross-sectional analysis of data from CAD patients aged 50-75 years just before starting a cardiac rehabilitation exercise program at the University Health Network-Toronto Rehabilitation Institute (UHN-Toronto Rehab), Toronto, Canada. All recruited participants had CAD, defined as a previous hospitalization for acute myocardial infarction, coronary angiographic evidence of $\geq 50 \%$ blockage in one or more major coronary artery, or prior revascularization. Only CAD patients currently being treated with statins were included in this study. The diagnosis of dyslipidemia was assumed (current statin use). Patients with any duration of previous statin exposure were included, and statin duration was described in the results of this study. Participants were excluded if they had previously diagnosed neurodegenerative illness (including dementia), active cancer, surgery planned within 12 months, schizophrenia, bipolar affective disorder, or substance abuse. The Mini Mental Status Examination (MMSE) was used to screen for dementia and subjects with MMSE $<24$ were excluded. ${ }^{31}$ A complete description of eligibility criteria and recruitment has been previously reported. ${ }^{32}$ The protocol, including acquisition of written informed consent, for this prospective study was approved by the Sunnybrook Health Sciences Centre Research Ethics Board and the University Health Network Research Ethics Board.

\section{LDL and statin exposures}

The main exposure was serum LDL levels. This study examined associations with the outcomes primarily using a dichotomous LDL definition (LDL $<1.5 \mathrm{mmol} / \mathrm{L}$ ), but also explored relationships using continuous measures. This dichotomous threshold for low LDL was chosen because of the high frequency of $\mathrm{LDL}<2.0 \mathrm{mmol} / \mathrm{L}$ in statin-treated CAD patients ${ }^{33}$ and data suggesting that cognition/brain functioning is theoretically most adversely affected when LDL serum concentrations are $<1.5 \mathrm{mmol} / \mathrm{L}$. ${ }^{1,34}$

The secondary exposure variable was high-dose versus low-dose statin use. High dose was defined as atorvastatin, pravastatin, or fluvastatin $40-80 \mathrm{mg} /$ day and rosuvastatin or simvastatin 20-40 mg/day, whereas lower dose was defined as $10-20 \mathrm{mg} /$ day and $5-10 \mathrm{mg}$ /day of those medications, respectively. 


\section{Exploratory lipid profile and statin exposure variables}

This study explored other potential lipid profile exposures: HDL, non-HDL cholesterol, TC, TC/HDL ratio, and triglyceride levels. These factors have previously had both positive and negative associations with cognition, with high TC, low HDL, and low triglycerides being mostly associated with decreased cognition (where an association had been reported). ${ }^{13,30}$ This study also explored whether there was an association between 1) lipophilic statins (atorvastatin, lovastatin, simvastatin, pitavastatin) versus hydrophilic statins (pravastatin, rosuvastatin, fluvastatin) and 2) statin duration, on cognition.

\section{Covariates}

Data on potential covariates associated with cognition were collected, which included age, sex, education, ethnicity, employment, marital status, body mass index, hypertension, diabetes mellitus, hemoglobin A1c, CAD severity (\% blockage), concomitant heart failure, coronary artery bypass graft, smoking, alcohol, nonsteroidal anti-inflammatory drugs, platelet inhibitors (eg, clopidogrel), anti-coagulants, calcium channel blockers, beta-blockers, antiarrhythmics, diuretics, insulin/oral hypoglycemic, antioxidant use, omega-3, gingko biloba/policosanol, corticosteroid use, non-statin lipid-lowering agents (cholesterol absorption inhibitors and niacin), hormone replacement therapy, thyroid medications, antipsychotic use, and benzodiazepine/zopiclone use. Demographic, clinical characteristics, and a detailed medical history were collected from patient interviews, whereas cardiac, medical history, current use of concomitant medications, and cardiac health indicators (body mass, height, dyslipidemia, hypertension, diabetes mellitus, and waist circumference) were obtained from patient charts. Body mass index was calculated per standard definition [mas kg)/ height $\left.(\mathrm{m})^{2}\right]$.

\section{Cognitive testing}

A battery of cognitive tests was used to assess verbal memory, executive function, speed of processing, and visuospatial memory. Verbal memory was assessed using the California Verbal Learning Test, 2nd Edition (CVLT-II), which yields a sensitive measure of long delay free recall of a word list after $20 \mathrm{~min}$ in addition to measures of verbal learning (recall of a word list over five learning trials) and short delay free recall (recall of a word list after $10 \mathrm{~min}$ ). ${ }^{35}$ Tasks involving an executive component included the Trails-Making Test
Part B (Trails B) ${ }^{36}$ and the Controlled Oral Word Association test (COWAT) ${ }^{37}$ The Trails-Making Test Part A (Trails A) ${ }^{36}$ and the Digit Symbol-Coding task, a measure of complex attention and psychomotor speed from the Wechsler Adult Intelligence Scale, 3rd Edition, were used to assess speed of processing. ${ }^{38}$ Visuospatial memory was assessed using the Brief Visuospatial Memory Test-Revised, ${ }^{39}$ which yields a measure of visual learning and delayed recall. These instruments were chosen based on the National Institute of Neurological Disorders and Stroke and Canadian Stroke Network (NINDS-CSN) harmonized standards. ${ }^{35}$ All cognitive testing were performed by a trained researcher at a standardized time (09:30 AM $\pm 30 \mathrm{~min})$ and subjects refrained from eating or drinking any caffeine-containing beverages for at least $4 \mathrm{~h}$ before testing.

For each cognitive task, a $Z$-score was determined from published age- and sex-matched norms. $Z$-scores follow a normal distribution with a standard deviation (SD) of 1.0; higher $Z$-scores reflect better performance. $Z$-scores of related tests can be summed into composite $Z$-scores to reflect performance in a cognitive domain and avoid multiple comparisons.$^{40}$ For memory, Z-scores from the three CVLT-II outcomes (verbal learning and short and long delayed recall) were summed. For executive function, the $Z$-scores of the Trails B and COWAT were summed. The sum of Digit Symbol-Coding task and Trails A was used to represent speed of processing, whereas $Z$-scores for the two Brief Visiospatial Memory Test-Revised (BVMT-R) outcomes (visual learning and delayed recall) were summed for visuospatial memory. For global cognition, the Montreal Cognitive Assessment (MoCA) was used. ${ }^{41}$ Impairment in the cognitive domains was defined by a $Z$-score $\leq 1 \mathrm{SD}$ below the mean.

\section{Outcomes}

The primary outcome was global cognition (MoCA), and the secondary outcomes were cognitive domain $Z$-scores: verbal memory, visuospatial memory, executive function, and processing speed. Dichotomous outcome measures were analyzed: MoCA $<26$ points and $Z$-scores $\geq 1$ SD below the mean, respectively. The dichotomous outcome measures were used as these would capture more clinically meaningful deficits in cognition.

Usually, cognitive domain $Z$-score thresholds $>1.5$ or $>2 \mathrm{SD}$ below the mean have been traditionally used in defining mild cognitive impairment. ${ }^{42}$ However, the study samples, although diagnosed with $\mathrm{CAD}$, were situated in a wealthy borough of metropolitan Toronto, were highly educated, 
and had substantially higher cognition than most CAD patients. ${ }^{42,43}$ Therefore, a more sensitive, while still clinically meaningful, cognitive $Z$-score threshold of $>1$ SD below the mean was chosen. The use of $>1$ SD below the mean has also been used in older adults with comparatively unimpaired cognition ${ }^{44}$ and adults with neuropsychiatric conditions, ${ }^{45}$ as well as in a cerebrovascular disease sample. ${ }^{46}$

\section{Data analysis}

Continuous variables were summarized as mean values and SDs, and categorical variables were presented as percentages. Associations between covariates and cognitive outcomes were assessed using chi-square analysis and analyses of variance (cognition $\leq 1 \mathrm{SD}$ below the mean). In addition to age, sex, and education, covariates with significant associations (two-tailed $P<0.05$ ) were included in the multivariable logistic regression as appropriate.
To test the main and secondary hypotheses, multivariable logistic regressions were performed to assess the association between $\mathrm{LDL}<1.5 \mathrm{mmol} / \mathrm{L}$ and cognitive outcomes and to assess the relationship between high-dose statin use and cognitive outcomes. SPSS 22.0 was used for all analyses.

\section{Results}

\section{Main hypothesis: LDL concentration and cognition in CAD patients}

Of the 120 patients, $54 \%$ had LDL $<1.5 \mathrm{mmol} / \mathrm{L}(\mathrm{n}=65)$. Those with LDL $<1.5 \mathrm{mmol} / \mathrm{L}$ were more likely to be male $\left(\chi^{2}[1]=4.76, P=0.03\right)$, less likely to have diabetes $\left(\chi^{2}[1]=8.22\right.$, $P=0.004)$, or have a percutaneous coronary angioplasty (PTCA) stent $\left(\chi^{2}[1]=8.67, P=0.003\right)$. Other demographic and clinical characteristics are described in Table 1.

In logistic regressions controlling for covariates (age, sex, years of education, diabetes, PTCA stent), there was

Table I Clinical and demographic characteristics of CAD patients using statins $(n=120)$

\begin{tabular}{|c|c|c|}
\hline \multirow[t]{2}{*}{ Variables } & \multirow{2}{*}{$\begin{array}{l}\text { LDL }<1.5 \mathrm{mmol} / \mathrm{L}(\mathrm{n}=65) \\
\text { Mean } \pm \text { SD or } \%(\mathrm{n})\end{array}$} & \multirow{2}{*}{$\begin{array}{l}\mathrm{LDL} \geq 1.5 \mathrm{mmol} / \mathrm{L}(\mathrm{n}=55) \\
\text { Mean } \pm \mathrm{SD} \text { or } \%(\mathrm{n})\end{array}$} \\
\hline & & \\
\hline Age, years & $63 \pm 7$ & $64 \pm 6$ \\
\hline Sex (\% male $)$ & $78.5(5 \mathrm{I})$ & $92.7(5 \mathrm{I})$ \\
\hline Education, years & $17 \pm 3$ & $16 \pm 4$ \\
\hline Ethnicity (\% Caucasian) & $87.7(57)$ & $78.2(43)$ \\
\hline Employment (\% employed) & $63.1(4 I)$ & $47.2(25)$ \\
\hline Marital status (\% married) & $69.2(45)$ & $72.7(40)$ \\
\hline Body mass index & $28.9 \pm 4.5$ & $29.5 \pm 5.8$ \\
\hline Hypertension & $95.4(62)$ & $92.7(5 \mathrm{I})$ \\
\hline Diabetes mellitus & $7.7(5)$ & $27.3(15)$ \\
\hline Hemoglobin Alc & $0.059 \pm 0.006$ & $0.059 \pm 0.001$ \\
\hline CAD severity (number of blocked vessels) & $2 \pm 1$ & $2 \pm 1$ \\
\hline Heart failure & $0(0)$ & $3.6(2)$ \\
\hline Myocardial infarction & $44.6(29)$ & $52.7(29)$ \\
\hline Coronary artery bypass graft & $27.3(15)$ & $38.5(25)$ \\
\hline Stent & $21.8(12)$ & $78.2(43)$ \\
\hline Smoking history (\% past or current smoker) & $66.2(43)$ & $54.5(30)$ \\
\hline Alcohol (number of drinks per week) & $3 \pm 4$ & $3 \pm 5$ \\
\hline Caffeine (number of caffeinated drinks per day) & $2 \pm 1.5$ & $2 \pm 2.5$ \\
\hline Depression (major and minor) & $12.7(7)$ & $24.6(16)$ \\
\hline Nonsteroidal anti-inflammatory drugs & $3.1(2)$ & $0(0)$ \\
\hline Corticosteroids & $0(0)$ & $1.8(1)$ \\
\hline Platelet inhibitors (eg, clopidogrel) & $95.4(62)$ & $98.2(54)$ \\
\hline Anti-coagulants & $7.7(5)$ & $1.8(1)$ \\
\hline Calcium channel blockers & $13.8(9)$ & $14.5(8)$ \\
\hline Beta-blockers & $80(52)$ & $80(44)$ \\
\hline Antiarrhythmics & $4.6(3)$ & $1.8(1)$ \\
\hline Diuretics & $20(13)$ & $10.9(6)$ \\
\hline Insulin use & $6.2(4)$ & $23.6(13)$ \\
\hline Non-statin lipid-lowering agents & $7.7(5)$ & $3.6(2)$ \\
\hline Antioxidant use & $9.1(5)$ & $18.5(12)$ \\
\hline Omega-3 & $25(15)$ & $22.4(11)$ \\
\hline Hormone replacement therapy & $0(0)$ & $1.8(\mathrm{I})$ \\
\hline Thyroid medications & $12.3(8)$ & $5.5(3)$ \\
\hline Anxiolytic use & $6.2(4)$ & $0(0)$ \\
\hline Alternative medicine & $0(0)$ & $0(0)$ \\
\hline
\end{tabular}

Abbreviations: CAD, coronary artery disease; LDL, low-density lipoprotein; SD, standard deviation. 
Table 2 Odds ratio of impairment $<$ I SD in cognitive domains between CAD patients with LDL $<$ I.5 mmol/L and those with $\mathrm{LDL} \geq 1.5 \mathrm{mmol} / \mathrm{L}$

\begin{tabular}{llll}
\hline Cognitive domains & $\begin{array}{l}\text { LDL }<\mathbf{I . 5} \mathbf{~ m m o l} / \mathbf{L} \\
\text { OR }(\mathbf{9 5} \% \mathbf{C l}) \\
\mathbf{n}=\mathbf{6 5}\end{array}$ & $\begin{array}{l}\text { LDL } \geq I .5 \text { mmol/L } \\
\text { (reference) } \\
\mathbf{n = 5 5}\end{array}$ & $\begin{array}{l}\boldsymbol{P} \text {-value } \\
\text { (significance } \\
\text { at } \mathbf{P} \leq \mathbf{0 . 0 5})\end{array}$ \\
\hline Global cognition & $1.78(0.76-4.20)$ & 1.0 & 0.19 \\
Verbal memory & $2.11(0.68-6.54)$ & 1.0 & 0.19 \\
Visuospatial memory & $1.57(0.46-5.29)$ & 1.0 & 0.47 \\
Processing speed & $0.76(0.27-2.19)$ & 1.0 & 0.62 \\
Executive function & $1.01(0.35-2.90)$ & 1.0 & 0.99 \\
\hline
\end{tabular}

Notes: aTwo-tailed significance of differences in cognitive impairment between LDL groups in logistic regressions controlling for age, gender, years of education, percutaneous coronary intervention, and diabetes.

Abbreviations: $\mathrm{CAD}$, coronary artery disease; $\mathrm{Cl}$, confidence interval; LDL, low-density lipoprotein; OR, odds ratio; SD, standard deviation.

no association between lower LDL concentrations and risk of impairment in global cognition (OR $[95 \% \mathrm{CI}]=0.56$ [0.24-1.32], $P=0.19)$, verbal memory $(\mathrm{OR}=0.47[0.15-1.47]$, $P=0.19)$, visuospatial memory $(\mathrm{OR}=0.64[0.19-2.16], P=0.47)$, processing speed $(\mathrm{OR}=1.31[0.46-3.76], P=0.62)$, or executive functioning $(\mathrm{OR}=1.00$ [0.35-2.87], $P=0.99)$ (Table 2). Similarly, LDL as a continuous measure was not associated with global cognition or any of the cognitive domain Z-scores (data not shown).

\section{Secondary hypothesis: high-dose versus low-dose statin use and cognition in CAD patients}

Seventy-four patients were high-dose statin users, while the remainder were low-dose statin users $(n=42)$. These 116 patients were used to examine statin dose and cognition: of all the 120 statin-using CAD patients in this study, four did not have statin dose information. The average duration of previous statin exposure was $25 \pm 43$ months (range: 1-200 months). Compared to low-dose users, highdose statin users were more likely to have had myocardial infarction ( $70 \%$ vs $\left.30 \%, \chi^{2}[1]=4.16, P=0.05\right)$, to be taking an antihypertensive medication $\left(70 \%\right.$ vs $30 \%, \chi^{2}[1]=3.96$, $P=0.06)$ and they were significantly younger ( $63 \pm 6$ years vs $66 \pm 6$ years; $F=7.05, P=0.01$ ).
In logistic regressions controlling for covariates (age, sex, years of education, myocardial infarction, anti-hypertensive use, serum LDL concentration, and duration of statin use), high-dose statin use was associated with a lower risk of impairment in visuospatial memory $(\mathrm{OR}=0.12[0.02-0.66], P=0.01)$ and executive functioning ( $\mathrm{OR}=0.25[0.06-0.99], P=0.05$ ) but not verbal memory $(\mathrm{OR}=1.78[0.47-6.72], P=0.39)$, processing speed $(\mathrm{OR}=0.41[0.13-1.29], P=0.13)$, and global cognition ( $\mathrm{OR}=1.11$ [0.42-2.93], $P=0.84)$ (Table 3$)$.

\section{Exploratory hypothesis: additional lipid profile variables and cognition}

The exploratory analyses did not find any association between HDL, non-HDL cholesterol, TC, TC/HDL ratio, triglyceride levels, and lipophilic statin use with either global cognition or cognitive domain $Z$-scores (data not shown).

\section{Discussion}

This study found that low LDL levels were not associated with decreased cognition in CAD patients using statins. This is important because CAD patients are at high risk of cognitive dysfunction ${ }^{21-24}$ and many CAD patients, particularly statin users, frequently have low LDL concentrations. The findings of this study are consistent with several welldesigned and well-powered studies that also did not find

Table 3 Odds ratio of impairment $<$ I SD in cognitive domains between CAD patients taking low-dose statins and those taking high-dose statins

\begin{tabular}{|c|c|c|c|}
\hline Cognitive domains & $\begin{array}{l}\text { Low-dose statin } \\
\text { (reference) }\end{array}$ & $\begin{array}{l}\text { High-dose statin } \\
\text { OR }(95 \% \mathrm{Cl})\end{array}$ & $\begin{array}{l}P \text {-value }{ }^{a} \\
\text { (significance at } P \leq 0.05 \text { ) }\end{array}$ \\
\hline Global cognition & 1.0 & I.II (0.42-2.93) & 0.84 \\
\hline Verbal memory & 1.0 & I.78 (0.47-6.72) & 0.39 \\
\hline Visuospatial memory & 1.0 & $0.12(0.02-0.66)$ & 0.01 \\
\hline Processing speed & 1.0 & $0.4 \mid(0.13-1.29)$ & 0.13 \\
\hline Executive function & 1.0 & $0.25(0.06-0.99)$ & 0.05 \\
\hline
\end{tabular}

Notes: a Two-tailed significance of differences in cognitive impairment between statin dose groups in logistic regressions controlling for age, gender, years of education, myocardial infarction, antihypertensive use, serum LDL concentrations, and duration of statin use.

Abbreviations: CAD, coronary artery disease; Cl, confidence interval; LDL, low-density lipoprotein; OR, odds ratio; SD, standard deviation. 
an association between LDL and cognition ${ }^{15-17}$ in general, though those studies had not been performed specifically in patients with CAD. At least from this initial study, it appears that $\mathrm{CAD}$ patients can be safely treated with statins to relatively low LDL levels $(<1.5 \mathrm{mmol} / \mathrm{L})$ without concern about cognition, although future longitudinal studies will be helpful to confirm this.

It was also found that high-dose statin use was associated with better visuospatial memory, processing speed, and executive function in CAD patients. This effect seemed to be most robust for visuospatial memory and was independent of covariates such as LDL. This article extends findings from recent meta-analyses and high-quality studies suggesting that statins are associated with lower cognitive risk. ${ }^{1-4}$ One paper had previously assessed whether there was any potential relationship between statin dose and cognition. ${ }^{47}$ That large observational study of 4,095 community-dwelling participants aged 35-82 years, including 904 statin users, did not find an association between statin use, dose, or duration with their measured cognitive outcomes: the Ruff Figural Fluency Test and the Visual Association Test. ${ }^{47}$ It is possible that the in-depth cognitive testing in this study allowed more sensitivity to detect effects on global cognition and cognitive domain scores. Further studies will be needed to replicate these findings and better understand the relationship that was observed between high-dose statin use and higher cognitive function. If this is replicated, it is hypothesized that the potential protective effect of high-dose statins on cognition may be unrelated to statins' effect on LDL. Instead, it is hypothesized that high-dose statins may potentially have positive effects on cognition in CAD patients through an extension of its antioxidant, endothelium-promoting, and anti-inflammatory effects observed at lower doses. ${ }^{18,19}$ Such statin effects may be mediated by modified intracellular signaling, particularly the inhibition of small guanosine triphosphate-binding proteins. ${ }^{9}$

\section{Strengths and limitations}

This study had a number of strengths. The patient sample was well-characterized in terms of in-depth cognitive testing and covariates specifically relevant to CAD. The sample size was comparable to other detailed studies of cognition and large enough to detect clinically important effects. There were also some limitations to the data. As this is an observational cross-sectional design, causality cannot be inferred. Medications use covariates that were based on current use and not previous use. There was no access to data regarding whether patients switched between high- and low-dose statin use during their previous exposure. Longitudinal and ideally randomized controlled study designs would be necessary to strengthen the findings of this study.

\section{Conclusion}

Low LDL levels do not appear to be associated with poor cognition in CAD patients using statins. This is reassuring given the high frequency of LDL concentrations $<1.5 \mathrm{mmol} / \mathrm{L}$ in CAD patients who are vulnerable to cognitive decline and dementia. High-dose statin use was found to be associated with better executive function and visuospatial cognition in CAD patients, which could be further investigated in future longitudinal and randomized controlled studies.

\section{Acknowledgments}

Funding support was provided by Canadian Institutes of Health Research (Lanctot MOP-114913) and the Heart and Stroke Foundation Canadian Partnership for Stroke Recovery.

\section{Disclosure}

Soham Rej receives salary support from the Canadian Institute of Health research (CIHR) Fellowship Award. Mahwesh Saleem was supported by funding from the Alzheimer's Society of Canada. Nathan Herrmann is supported by peerreviewed grants from the Alzheimer Society of Canada (grant 15-17), Canadian Institute of Health Research, Heart and Stroke Foundation (grant T 6383), Ontario Ministry of Health and Long Term Care AFP Provincial Innovation Fund and Ontario Brain Institute in addition to research contracts funded by F Hoffman-La Roche Ltd. and Lundbeck Canada Inc. Krista L Lanctôt is supported by peer-reviewed grants from the Alzheimer Society of Canada (grant 15-17), Alzheimer's Drug Discovery Foundation (grant 20140503), Canadian Institute of Health Research, National Institute on Aging of the National Institutes of Health (grant R01AG046543), and the Heart and Stroke Foundation (grant NA 7220) in addition to research contracts funded by AbbVie Pharmaceuticals, F Hoffman-LaRoche Ltd., Elan Pharma International Ltd., and Lundbeck Canada Inc. Anthi Stefatos and Allison Rau report no conflicts of interest in this work.

\section{References}

1. Lilly SM, Mortensen EM, Frei CR, Pugh MJ, Mansi IA. Comparison of the risk of psychological and cognitive disorders between persistent and nonpersistent statin users. Am J Cardiol. 2014;114(7):1035-1039.

2. Swiger KJ, Manalac RJ, Blumenthal RS, Blaha MJ, Martin SS. Statins and cognition: a systematic review and meta-analysis of short- and longterm cognitive effects. Mayo Clin Proc. 2013;88(11):1213-1221. 
3. Hendrie HC, Hake A, Lane K, et al. Statin use, incident dementia and Alzheimer disease in elderly African Americans. Ethn Dis. 2015;25(3): 345-354.

4. Yaffe K, Barrett-Connor E, Lin F, Grady D. Serum lipoprotein levels, statin use, and cognitive function in older women. Arch Neurol. 2002; 59(3):378-384.

5. Nadkarni NK, Perera S, Hanlon JT, et al. Statins and brain integrity in older adults: secondary analysis of the Health ABC study. Alzheimers Dement. 2015;11(10):1202-1211.

6. McGuinness B, Craig D, Bullock R, Passmore P. Statins for the prevention of dementia. Cochrane Database Syst Rev. 2016;1:CD003160.

7. Carlsson CM, Gleason CE, Hess TM, et al. Effects of simvastatin on cerebrospinal fluid biomarkers and cognition in middle-aged adults at risk for Alzheimer's disease. J Alzheimers Dis. 2008;13(2):187-197.

8. Sparks DL, Connor DJ, Sabbagh MN, Petersen RB, Lopez J, Browne P. Circulating cholesterol levels, apolipoprotein E genotype and dementia severity influence the benefit of atorvastatin treatment in Alzheimer's disease: results of the Alzheimer's Disease Cholesterol-Lowering Treatment (ADCLT) trial. Acta Neurol Scand Suppl. 2006;185:3-7.

9. Liao JK, Laufs U. Pleiotropic effects of statins. Ann Rev Pharmacol Toxicol. 2005;45:89-118.

10. Freemantle E, Mechawar N, Turecki G. Cholesterol and phospholipids in frontal cortex and synaptosomes of suicide completers: relationship with endosomal lipid trafficking genes. J Psychiatr Res. 2013;47(2): $272-279$.

11. Wang SH, Huang Y, Yuan Y, Xia WQ, Wang P, Huang R. LDL receptor knock-out mice show impaired spatial cognition with hippocampal vulnerability to apoptosis and deficits in synapses. Lipids Health Dis 2014; $13: 175$.

12. Mandas A, Congiu MG, Abete $\mathrm{C}$, et al. Cognitive decline and depressive symptoms in late-life are associated with statin use: evidence from a population-based study of Sardinian old people living in their own home. Neurol Res. 2014;36(3):247-254.

13. Ancelin ML, Ripoche E, Dupuy AM, et al. Gender-specific associations between lipids and cognitive decline in the elderly. Eur Neuropsychopharmacol. 2014;24(7):1056-1066.

14. Leritz EC, McGlinchey RE, Salat DH, Milberg WP. Elevated levels of serum cholesterol are associated with better performance on tasks of episodic memory. Metab Brain Dis. 2016;31(2):465-473.

15. Koyama A, Stone K, Yaffe K. Serum oxidized low-density lipoprotein level and risk of cognitive impairment in older women. Neurobiol Aging. 2013;34(2):634-635.e632.

16. Ott BR, Daiello LA, Dahabreh IJ, et al. Do statins impair cognition? A systematic review and meta-analysis of randomized controlled trials. J Gen Intern Med. 2015;30(3):348-358.

17. Chitnis AS, Aparasu RR, Chen H, Kunik ME, Schulz PE, Johnson ML. Use of statins and risk of dementia in heart failure: a retrospective cohort study. Drugs Aging. 2015;32(9):743-754.

18. Griffiths H, Irundika D, Lip G, Spickett C, Polidori C. Oxidised LDL lipids, statins and a blood-brain barrier. Free Radic Biol Med. 2014; 75(Suppl 1):S15-S16.

19. Dias HK, Brown CL, Polidori MC, Lip GY, Griffiths HR. LDL-lipids from patients with hypercholesterolaemia and Alzheimer's disease are inflammatory to microvascular endothelial cells: mitigation by statin intervention. Clin Sci (Lond). 2015;129(12):1195-1206.

20. Hagenaars SP, Harris SE, Clarke TK, et al. Polygenic risk for coronary artery disease is associated with cognitive ability in older adults. Int $J$ Epidemiol. Epub 2016 Jan 28.

21. Justin BN, Turek M, Hakim AM. Heart disease as a risk factor for dementia. Clin Epidemiol. 2013;5:135-145.

22. Rusanen M, Kivipelto M, Levalahti E, et al. Heart diseases and longterm risk of dementia and Alzheimer's disease: a population-based CAIDE study. J Alzheimers Dis. 2014;42(1):183-191.

23. Newman AB, Fitzpatrick AL, Lopez O, et al. Dementia and Alzheimer's disease incidence in relationship to cardiovascular disease in the Cardiovascular Health Study cohort. J Am Geriatr Soc. 2005;53(7):1101-1107.
24. Kovacic JC, Castellano JM, Fuster V. The links between complex coronary disease, cerebrovascular disease, and degenerative brain disease. Ann N Y Acad Sci. 2012;1254:99-105.

25. Santiago C, Herrmann N, Swardfager W, et al. White matter microstructural integrity is associated with executive function and processing speed in older adults with coronary artery disease. Am J Geriatr Psychiatry. 2015;23(7):754-763.

26. Vidal JS, Sigurdsson S, Jonsdottir MK, et al. Coronary artery calcium, brain function and structure: the AGES-Reykjavik Study. Stroke. 2010;41(5):891-897.

27. Pursnani A, Massaro JM, D’Agostino RB Sr, O’Donnell CJ, Hoffmann U. Guideline-based statin eligibility, coronary artery calcification, and cardiovascular events. JAMA. 2015;314(2):134-141.

28. Trubnikova OA, Tarasova IV, Mamontova AS, Kagan ES, Maleva OV, Barbarash OL. [Predictors of moderate cognitive disorders in patients with coronary heart disease and type 2 diabetes mellitus]. Klinicheskaia Meditsina. 2016;94(1):31-35. Russian.

29. Benjo AM, El-Hayek GE, Messerli F, et al. High dose statin loading prior to percutaneous coronary intervention decreases cardiovascular events: a meta-analysis of randomized controlled trials. Catheter Cardiovasc Interv. 2015;85(1):53-60.

30. Yin ZX, Shi XM, Kraus VB, et al. High normal plasma triglycerides are associated with preserved cognitive function in Chinese oldest-old. Age Ageing. 2012;41(5):600-606

31. Cacciatore F, Abete P, Maggi S, et al. Disability and 6-year mortality in elderly population. Role of visual impairment. Aging Clin Exp Res. 2004; 16(5):382-388.

32. Swardfager W, Herrmann N, Marzolini S, et al. Verbal memory performance and completion of cardiac rehabilitation in patients with coronary artery disease. Psychosom Med. 2011;73(7):580-587.

33. Vonbank A, Saely CH, Rein P, Drexel H. Lipid parameters in patients with acute coronary syndromes versus stable coronary artery disease. Eur J Clin Invest. 2015;45(10):1092-1097.

34. Kale AB, Kale SB, Chalak SS, et al. Lipid parameters - significance in patients with endogenous depression. J Clin Diagn Res. 2014;8(1): 17-19.

35. Hachinski V, Iadecola C, Petersen RC, et al. National Institute of Neurological Disorders and Stroke-Canadian Stroke Network vascular cognitive impairment harmonization standards. Stroke. 2006;37(9): $2220-2241$

36. Gaudino EA, Geisler MW, Squires NK. Construct validity in the trail making test: what makes part B harder? J Clin Exp Neuropsychol. 1995; 17(4):529-535.

37. Ruff RM, Light RH, Parker SB, Levin HS. Benton controlled oral word association test: reliability and updated norms. Arch Clin Neuropsychol. 1996;11(4):329-338.

38. Joy S, Kaplan E, Fein D. Speed and memory in the WAIS-III Digit Symbol - Coding subtest across the adult lifespan. Arch Clin Neuropsychol. 2004;19(6):759-767.

39. Benedict RH, Schretlen D, Groninger L, Dobraski M, Shpritz B. Revision of the brief visuospatial memory test: studies of normal performance, reliability, and validity. Psychol Assess. 1996;8(2):9.

40. Harrison J, Minassian SL, Jenkins L, Black RS, Koller M, Grundman M. A neuropsychological test battery for use in Alzheimer disease clinical trials. Arch Neurol. 2007;64(9):1323-1329.

41. Nasreddine ZS, Phillips NA, Bedirian V, et al. The Montreal Cognitive Assessment, MoCA: a brief screening tool for mild cognitive impairment. J Am Geriatr Soc. 2005;53(4):695-699.

42. Schinka JA, Loewenstein DA, Raj A, et al. Defining mild cognitive impairment: impact of varying decision criteria on neuropsychological diagnostic frequencies and correlates. Am J Geriatr Psychiatry. 2010; 18(8):684-691.

43. Santiago C, Herrmann N, Swardfager W, et al. White matter microstructural integrity is associated with executive function and processing speed in older adults with coronary artery disease. Am J Geriatr Psychiatry. 2015;23(7):754-763. 
44. Koekkoek PS, Rutten GE, van den Berg E, et al. The "Test Your Memory" test performs better than the MMSE in a population without known cognitive dysfunction. J Neurol Sci. 2013;328(1-2):92-97.

45. Lam RW, Iverson GL, Evans VC, et al. The effects of desvenlafaxine on neurocognitive and work functioning in employed outpatients with major depressive disorder. J Affect Disord. 2016;203:55-61.

46. Umemura T, Kawamura T, Umegaki H, et al. Endothelial and inflammatory markers in relation to progression of ischaemic cerebral smallvessel disease and cognitive impairment: a 6-year longitudinal study in patients with type 2 diabetes mellitus. J Neurol Neurosurg Psychiatry. 2011;82(11):1186-1194.
47. Joosten H, Visser ST, van Eersel ME, et al. Statin use and cognitive function: population-based observational study with long-term follow-up. PLoS One. 2014;9(12):e115755.

\section{Publish your work in this journal}

Neuropsychiatric Disease and Treatment is an international, peerreviewed journal of clinical therapeutics and pharmacology focusing on concise rapid reporting of clinical or pre-clinical studies on a range of neuropsychiatric and neurological disorders. This journal is indexed on PubMed Central, the 'PsycINFO' database and CAS, and is the official journal of The International Neuropsychiatric Association (INA). The manuscript management system is completely online and includes a very quick and fair peer-review system, which is all easy to use. Visit http://www.dovepress.com/testimonials.php to read real quotes from published authors.

Submit your manuscript here: http://www.dovepress.com/neuropsychiatric-disease-and-treatment-journal 